International Journal of Advanced Academic Research (Business and Economic Development) | ISSN: 2488-9849

Vol. 6, Issue 11 (November, 2020) | www.ijaar.org

Journal DOI: 10.46654/ij.24889849

Article DOI: 10.46654/ij.24889849.b61120

\title{
STRATEGIC FLEXIBILITY AND ORGANIZATIONAL INNOVATIVENESS OF DEPOSIT MONEY BANKS IN RIVERS STATE
}

\author{
Green Soprinye Dublin \\ University of Port Harcourt Business School, Port Harcourt, Rivers State, Nigeria. \\ B. Chima Onuoha \\ Department of Management, \\ University of Port Harcourt, Choba, Port Harcourt, Rivers State, Nigeria.
}

\begin{abstract}
This paper addressed the relationship between strategic flexibility and organizational innovativeness of tier 1 banks in Rivers State. The objectives of the study were to ascertain the role of three dimensions of strategic flexibility (resource orientation, robustness and agility) in the actualization of organizational innovativeness in the deposit money banks of interest. 5 banks were captured as the population of the study with 38 managers serving as units of measurement in the study. Primary data was generated using the structured questionnaire from the specified units of measurement with instruments assessed for reliability using the Cronbach alpha coefficient. Results demonstrated all instruments to be highly reliable. The Spearman's rank order correlation coefficient was utilized in the test for the hypotheses of the study with results demonstrating significant and positive relationships between the three dimensions of strategic flexibility and organizational innovativeness. Evidence based on the scatter diagram also demonstrated that strategic flexibility accounted for approximately 58\% changes in the organizational innovativeness of the deposit money banks in Rivers State. It was concluded that dimensions of strategic flexibility such as resource orientation, robustness and agility, all play significant roles in shaping the organization's operations and functionality within its context; such that contributes significantly towards enhancing outcomes of organizational innovativeness.
\end{abstract}

Keywords: Strategic flexibility, organizational innovativeness, robustness, agility, resource orientation. 


\section{INTRODUCTION}

Innovativeness is today considered a fundamental aspect of business organizations. This is because the survival of the organization depends on its capacity for creativity and inventiveness; drawing from the observed level of competition that currently defines the business environment of most developing nations such as Nigeria. Innovativeness is what, according to Hoq and $\mathrm{Ha}$ (2009) separates effective and successful organizations from underperforming organization. The growing interest in innovativeness is also justified on its link to the environment and hence the imperative for consistent learning and flexible actions geared towards enhancing the organization's capacity for effectively and creatively meeting the changing and dynamic needs and expectations of its market.

Literature on innovativeness abounds within the context of both product and service industries (Giniuniene \& Jurksiene, 2015; Hoq \& Ha, 2009). Studies show that innovativeness is linked to the organization's learning and change capacity (Fu, 2017). While most research have focused on the level of knowledge management and resourcefulness within the organization as prerequisites for innovativeness; it is important to note that the effectiveness of the organization and its capacity for innovation is strategic, implying that effective change behaviour is based on the organization's capacity for resource shifts and flexibility, robustness in times of turbulence or change and also agility in terms of matching services and operations to market shifts and changes. This is as Fu (2017) described such alterations in resources and behaviour as strategic flexibility; noting that it allows for a more effective anchoring of the organization with the changes in the environment.

Previous studies indicate that strategic flexibility also enhances the competitiveness of firms and allows them thrive in volatile and highly unpredictable contexts (Cingoza \& Akdogan, 2013; Doroudi \& Babaei, 2016). However, not much of empirical research, has linked outcomes of innovativeness to strategic flexibility, especially within the context of deposit money banks in Nigeria. This is as Duroudi and Babaei (2016) argued that the difficulties and problems resulting from the emerging markets, changing population demography and increasing competition as such that can be effectively addressed and controlled through learning and the effective integration of knowledge forms in the strategic behaviour of the organization; such that allows for flexibility in terms of resource orientation, robustness and agility. This study therefore investigates the role of strategic flexibility in the actualization of organizational innovativeness of deposit money banks in Rivers State, Nigeria. 


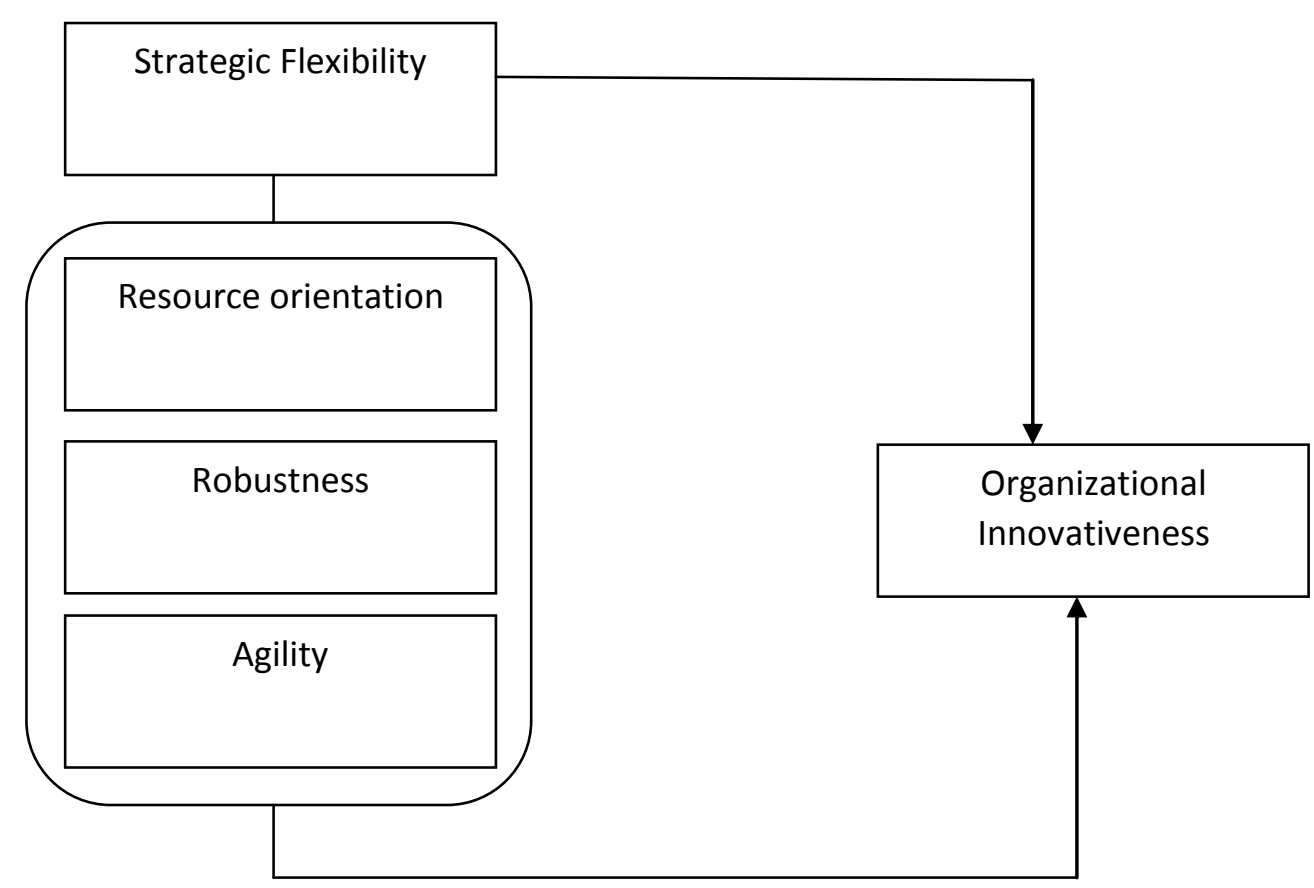

Figure 1: Conceptual framework for strategic flexibility and organizational innovativeness Source: Researcher's desk (2020)

\section{Aim and Objectives of the Study}

The aim of this paper is to investigate the role of strategic flexibility in the actualization of organizational innovativeness of deposit money banks in Rivers State. The objectives of the paper are to:

i. Determine the role of resource orientation in the actualization of organizational innovativeness of the deposit money banks in Rivers State

ii. Ascertain the role of robustness in the actualization of organizational innovativeness of the deposit money banks in Rivers State

iii. Examine the role of agility in the actualization of organizational innovativeness of the deposit money banks in Rivers State

\section{Research Questions}

The research questions for this paper are stated as follows:

i. What is the role of resource orientation in the actualization of organizational innovativeness of the deposit money banks in Rivers State?

ii. What is the role of robustness in the actualization of organizational innovativeness of the deposit money banks in Rivers State?

iii. What is the role of agility in the actualization of organizational innovativeness of the deposit money banks in Rivers State?

\section{Statement of Hypotheses}

HO1: Resource orientation does not significantly correlate with the organizational innovativeness of deposit money banks in Rivers State 
HO2: Robustness does not significantly correlate with the organizational innovativeness of deposit money banks in Rivers State

HO3: Agility does not significantly correlate with the organizational innovativeness of deposit money banks in Rivers State

\section{LITERATURE REVIEW}

Social Learning Theory: Cherry 2016) described the social learning theory as that which addresses the individual or organizations learning experience within a particular context and the resulting modification's to the behaviour and actions of the individual or organization in line with such learning. Likewise, Edinyang (2016) argued that the social learning theory, fundamentally addresses the relationship between the organization and its environment. Studies (Cherry, 2016; Muro \& Jeffrey, 2008) show support for the growing usefulness of the social learning theory in the prediction of organizational outcomes premised on their learning ability and also their capacity for transformation based on the outcomes of their learning. Muro and Jeffrey (2008) describe the social learning theory as integral to the organization's capacity for adapting in terms of service and product offerings to match the needs of the environment.

Raj and Srivastave (2013) Opined that learning is vital to the success of the organization. This is because learning offers direction to the organization in such a way that helps it identify the areas of concern in the design of its products and services. Kuo (2011) argued that for organizations to be able to compete favourably within their market, they must have good knowledge of such markets and must also be in tune with the trends and changes of the market (Jimenez-Jimenez \& Sanz-Valle, 2011; Awasthy and Gupta, 2012; Kuo, 2011). This is as Maktabi and Khazaei (2014) stated that learning is a deliberate action, just as the transformation of the organization as well. As such it details decisions and the channelling of resources into learning activities which address the changes in the environment and at the same time exploiting and applying the knowledge obtained for the required level of success in the innovativeness of the organization.

\section{Strategic Flexibility}

Alan et al. (2016) described strategic flexibility as the organization's capacity for change given the availing options and alternatives (Alan et al., 2016). Strategic flexibility describes the organization's varying options for action based on its relationships, the optimal utilization of its resources and also its pool of competency (Doroudi \& Babaei, 2016). Strategic flexibility is essential in advancing the competitiveness of the organization as it not only structures features that are highly fluid and as such able to adapt to the changes in the environment; but it also advances features solutions that build on the organization's own capacity for consistency with the changes in its environment (Rajala et al., 2012). It is therefore a key feature necessary for promoting the wellbeing of the organization in unpredictable situations and for enabling it survive turbulent periods. Three dimensions of strategic flexibility based on Alan et al. (2016) are discussed as follows:

Resource orientation: This describes the organization's focus on the development, and exploitation of its resources in its drive for change and competition. Alan et al. (2016) observed that the resource orientation of the organization emphasizes on the development of its workers and in the channelling of their creativity and skills towards improved organizational functionality and performance. 
Robustness: This dimension refers to the organization's capacity for sustained operations and functions despite sudden changes which may be unfavourable to the organization (Alan, et al., 2016). It describes the organization's capacity for effectiveness and performance as a result of its fluidity and consistency in matching environmental changes with suitable decisions, processes and practices as well.

Agility: Agility describes the organization's promptness and capacity for quick action in the face of change. This details the features of the structure and roles within the organization and the extent to which power and decision-making is centralized to allow for increased responsibility and actions at various levels within the organization. It also emphasizes on the need for participation (Alan et al., 2016).

\section{Organizational Innovativeness}

Organizational innovativeness according to Hassan et al. (2013) describes the organization's capacity for creative service and product offerings. It is a capacity and builds on the organization's competency and level of creativity. This is as Hoq and Ha (2009) opined that the development of innovativeness is anchored in the learning behaviour of the organization. According to them, learning can be described as the springboard for innovativeness as it facilitates knowledge and skill development. This is as $\mathrm{Fu}$ (2017) described it as the availing of a pool of creative and resourceful workers within the organization which drive its capacity for innovation. Organizational innovativeness is also a critical factor for the organization's sustained functionality and operational continuity within its context.

Giniuniene and Jurksiene (2015) noted that organizational innovativeness helps the organization by strengthening its customer base through improved inventiveness and as such enhanced customer satisfaction (Chang et al., 2006).Literature (Mahmoud et al., 2016) on organizational innovativeness describes the concept as being distinct from that of organizational innovation in the sense that, innovativeness expresses the organization's tendencies and capacity for renewal and creativity; innovation on the other hand is concerned with the organization's product and service outcome - especially in terms of their addressing evident satisfaction gaps in the environment. Hence, while innovativeness details the organization's capacity, innovation details the outcome of such capacity (Fu, 2017; Mahmoud et al., 2016).

\section{Strategic Flexibility and Organizational Innovativeness}

Cingoza and Akdogan (2013) opined that organizations are defined by their environment. Their success and operations within their contexts are linked to how well they understand and are able to modulate between their various options and alternatives. Organizations in this way are most effective when their decisions are in consonance with the existing structures and norms of their environment. Strategic flexibility can therefore be considered advantageous to the organization as it aligns its behaviour with the dynamics of its context. Organizations that reflect flexibility in their decisions and behaviour demonstrate their competency in relationships and role capability. Alan et al. (2016) noted that organizations through the availing pool of resources and their capacity to vary the usage of such resource; have a higher tendency to be innovative in their products and services. Such levels of flexibility demonstrate the organization's level of embeddedness and integration in its operational context and also indicate its strategic position within its market (Alan et al., 2016; Doroudi \& Babaei, 2016).

\section{Methodology}


This paper adopts the quasi-experimental approach, particularly the cross-sectional design in its investigation of the relationship between the variables. The population for the study is specified to all tier 1 banks operational within Rivers State; giving a total of 5 banks from which 40 managers and supervisors are identified as the units of measurement. The instrument for the study is the structured questionnaire which given the methodology of the study (quantitative) is considered adequate and suitable. Instrumentation for the constructs is adapted from previous studies and from existing empirical literature. A total of 4 items are utilized for each dimension of strategic flexibility (Alan, et al., 2016) while organizational innovativeness is also adapted from Hoq and Ha (2009). Reliability tests were also based on the Cronbach alpha item with summary scores suggesting good and clear instruments (resource orientation = 0.924 ; robustness $=0.911$; agility $=0.898$ and organizational innovativeness $=0.946$ ). All instruments are noted to exceed an adopted benchmark of 0.70 in line with Nunnally (cited in Sekaran, 2003).

\section{DATA RESULTS}

The result for the data distributions and analysis is presented in this section. While 40 copies of the questionnaire were initially distributed, only 38 copies were retrieved and considered as suitable in the investigation of interest. All 38 copies retrieved were considered as adequate and suitable (based on low error issues) for inclusion in the analysis of the study.

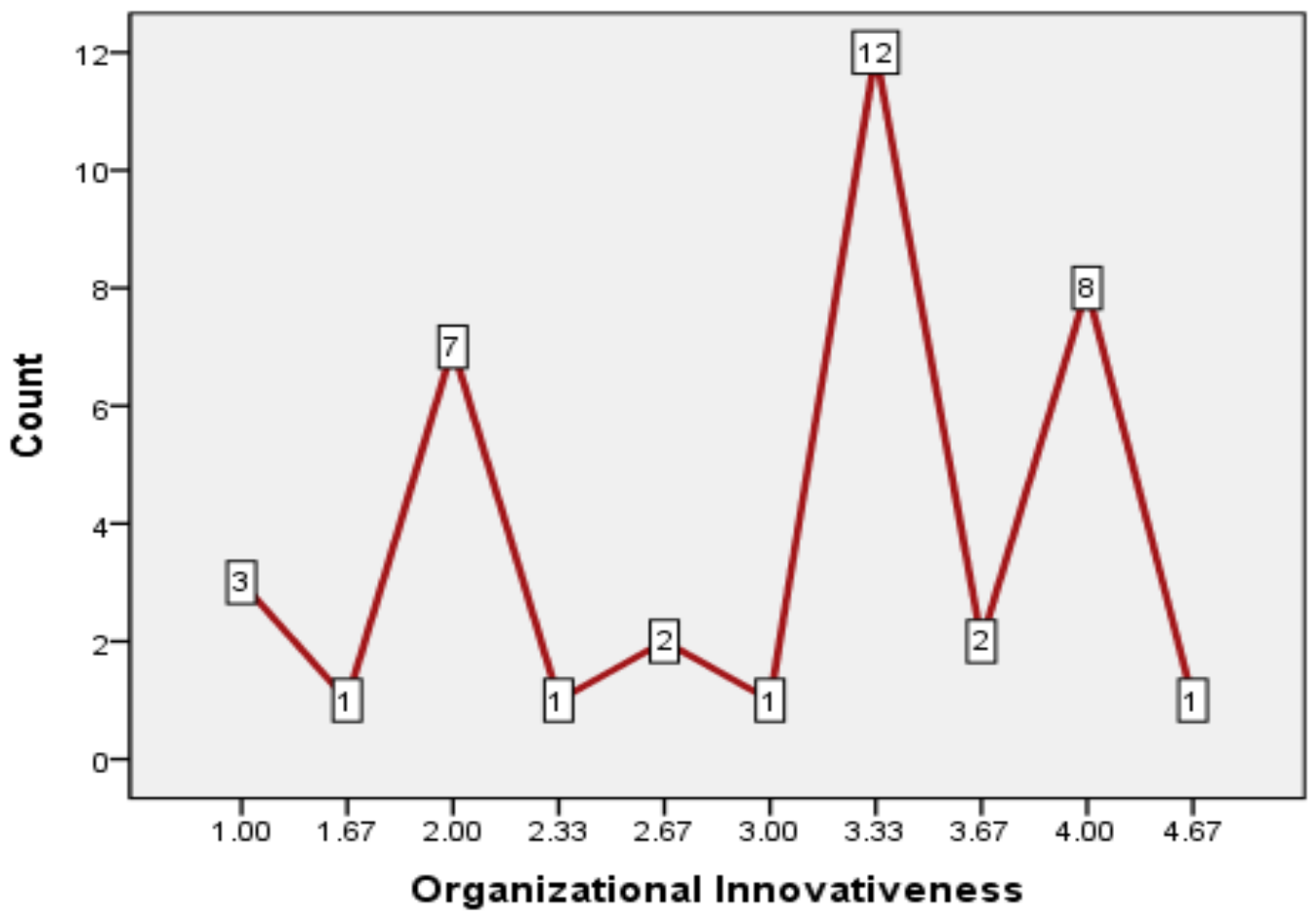

Figure 2: Line diagram for distribution for organizational innovativeness

The univariate summary data distribution for organizational innovativeness is presented in figure 2. Evidence demonstrates evidence of support and agreement to the variable as an attribute of the deposit money banks examined. Results suggest high levels of recognition of the variable within the context of the banks. 


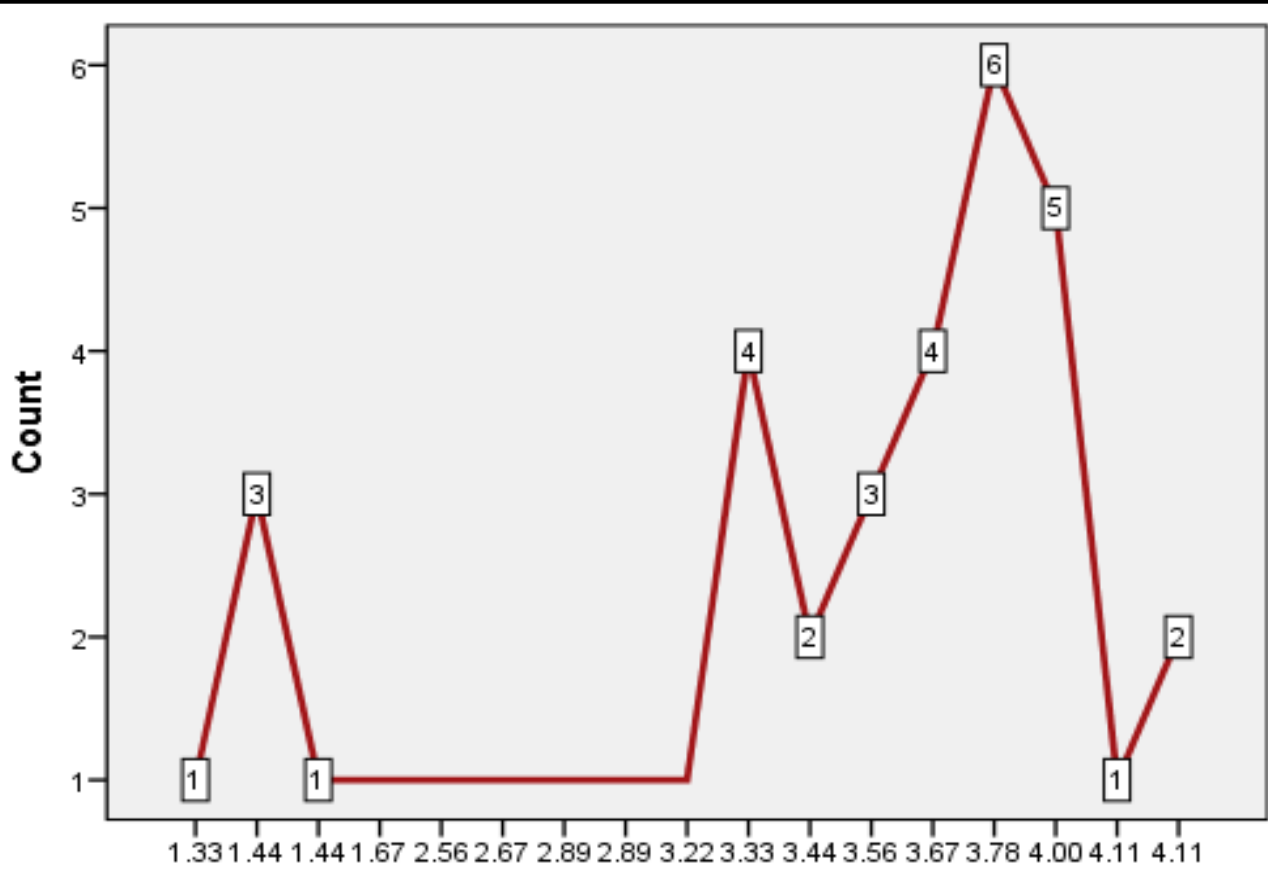

Strategic Flexibility

Figure 3: Line diagram for distribution for strategic flexibility

The univariate data distribution for strategic flexibility is illustrated on figure 3 with results demonstrating that the variable has a substantial level of manifestation and evidence within the context of interest. Results show that referents consider their banks as having strong evidence of characteristics reflecting strategic flexibility.

Bivariate Analysis: The bivariate analysis of the study assessed the nature and direction of the relationship between the dimensions of strategic flexibility (resource orientation, robustness and agility). The analysis also detailed the test for the hypotheses of the study using the Spearman's rank order correlation coefficient. Hypotheses are tested as two-tailed suggesting a non-directional assessment of the relationship between the variables.

Table 1: Hypotheses test result

\begin{tabular}{|c|c|c|c|c|c|c|}
\hline & & & $\begin{array}{l}\text { Resource } \\
\text { orientation }\end{array}$ & Robustness & Agility & $\begin{array}{l}\text { Organizational } \\
\text { Innovativeness }\end{array}$ \\
\hline \multirow{12}{*}{$\begin{array}{l}\text { Spearman' } \\
\text { s rho }\end{array}$} & \multirow{4}{*}{$\begin{array}{l}\text { Resource } \\
\text { orientation }\end{array}$} & Correlation Coefficient & 1.000 & $.654^{n}$ & .277 & .496 \\
\hline & & Sig. (2-tailed) & & .000 & .092 & .002 \\
\hline & & $\mathrm{N}$ & 38 & 38 & 38 & 38 \\
\hline & & Correlation Coefficient & $.654^{\pi \pi}$ & 1.000 & $.593^{\pi \pi}$ & $.648^{\pi \pi}$ \\
\hline & \multirow[t]{3}{*}{ Robustness } & Sig. (2-tailed) & .000 & & .000 & .000 \\
\hline & & $\mathrm{N}$ & 38 & 38 & 38 & 38 \\
\hline & & Correlation Coefficient & .277 & $.593^{\mathrm{xx}}$ & 1.000 & $.482^{x \times}$ \\
\hline & \multirow[t]{2}{*}{ Agility } & Sig. (2-tailed) & .092 & .000 & & .002 \\
\hline & & $\mathrm{N}$ & 38 & 38 & 38 & 38 \\
\hline & \multirow{3}{*}{$\begin{array}{l}\text { Organizational } \\
\text { Innovativeness }\end{array}$} & Correlation Coefficient & $.496^{\pi \pi}$ & $.648^{\pi \pi}$ & $.482^{\pi x}$ & 1.000 \\
\hline & & Sig. (2-tailed) & .002 & .000 & .002 & \\
\hline & & $\mathrm{N}$ & 38 & 38 & 38 & 38 \\
\hline
\end{tabular}

Source: Research survey, 2020

The result for the hypotheses test reveals strategic flexibility dimensions of resource orientation, robustness and agility as having significant relationships with organizational 
innovativeness. The evidence from the analysis demonstrates that at a rho $=0.496$ and $\mathrm{P}=$ 0.000 , the relationship between resource orientation and organizational innovativeness is significant and positive; at a rho $=0.648$ and $\mathrm{P}=0.000$, the relationship between robustness and organizational innovativeness is significant and positive; and at a rho $=0.482$ and $\mathrm{P}=$ 0.000 , the relationship between agility and organizational innovativeness is also significant and positive. Based on the evidence presented, all previous hypotheses are rejected.

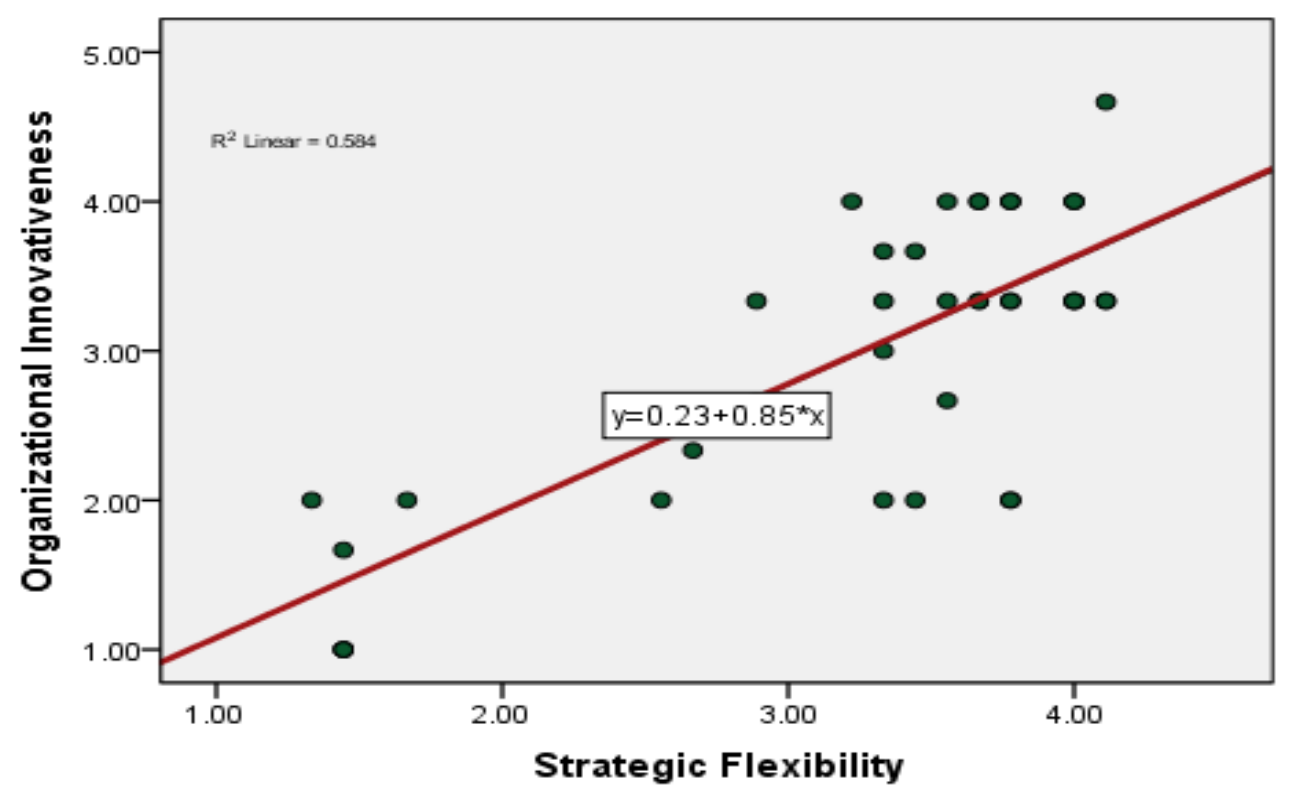

Figure 4: Scatter diagram for relationship between the variables

The scatter diagram of figure 4 above demonstrates the relationship between strategic flexibility and organizational innovativeness. The evidence identifies strategic flexibility as a substantial antecedent of organizational innovativeness; with approximately $58 \%$ of the changes in organizational innovativeness considered as being linked to practices and actions reflecting strategic flexibility

\section{DISCUSSION AND CONCLUSION}

The findings of this study offer insight as to the implications of strategic flexibility for outcomes of organizational innovativeness. Alan et al. (2016) in a similar assessment of the role of strategic flexibility in driving organizational performance highlighted on the need for organizational learning and the development of feedback loops from the environment as a way of building stronger coherence between organizational practices with the changes of the environment (Kamasak et al., 2016; Rajala et al., 2012). The result for test for the hypotheses showed that strategic flexibility demonstrated through resource orientation, robustness and agility, advances improved levels of creativity and opportunity exploration for the organization; and by that drives the innovativeness of firms; particularly deposit money banks in Rivers State.

This paper, based on its evidence, lends credence to the findings of previous research which have shown that strategic flexibility advances strategic outcomes for organizations that enables them function and compete more effectively with other organizations. The result from the analysis shows that, strategic flexibility is a prerequisite for increased levels of innovation by the deposit money banks. Drawing from the evidence presented, it is concluded that dimensions of strategic flexibility such as resource orientation, robustness and agility, all play 
International Journal of Advanced Academic Research (Business and Economic Development) | ISSN: 2488-9849

Journal DOI: 10.46654/ij.24889849

Vol. 6, Issue 11 (November, 2020) | www.ijaar.org

Article DOI: 10.46654/ij.24889849.b61120

significant roles in shaping the organization's operations and functionality within its context; such that contributes significantly towards enhancing outcomes of organizational innovativeness. 


\section{REFERENCES}

Alan, T.L.C., Ngai, E.W.T., Karen, K.L.M. (2016), The Effects of strategic and manufacturing flexibilities and supply chain agility on firm performance in the fashion industry. European Journal of Operational Research, 259, 1-14.

Awasthy, R.; and Gupta, R.K. (2012), Dimensions of The Learning Organization in an Indian Context, International Journal of Emerging Market, 7(3), 222-224.

Chang, S.; Chiang, C.; Chu, C.; and Wang, Y. (2006), The Study of Social Capital, Organizational Learning, Innovativeness, Intellectual Capital, and Performance, The Journal of Human Resource and Adult Learning, 64-71.

Cherry, K. (2016). What is social learning theory? Retrieved from https://www.verywell.com/social-learning-theory2795074

Cingöza, A., Akdoğan, A. (2013), Strategic flexibility, environmental dynamism, and innovation performance: An empirical study. Procedia-Social and Behavioral Sciences, 99, 582-589.

Doroudi, H., Babaei, L. (2016), A Study on the Relationship Between Strategic Planning Processes, Planning Flexibility, and Firm Performance: Considering the Mediating role of Innovation. Qom: International Conference on Economy, Management, and Psychology

Edinyang, S. D. (2016). The significance of social learning theories in the teaching of social studies education. International Journal of Sociology and Anthropology Research,2(1),40-45

$\mathrm{Fu}, \mathrm{H}$. (2017), Organizational Learning and Organization Innovation in the Tourist Hotels - An Empirical Study, EURASIA Journal of Mathematics Science and Technology Education, 13(9), 6347-6356

Giniuniene, J.; and Jurksiene, L. (2015), Dynamic Capabilities, Innovation and Organizational Learning: Interrelations and Impact on Firm Performance, Procedia - Social and Behavioural Sciences, 213(2015), 985-991.

Hassan, M.I.; Shaukat, S.; Nawaz, M.S.; and Naz, S. (2013), Effects on Innovation Types on Firm Performance: an Empirical study on Pakistan's Manufacturing Sector, Pakistan Journal of Commerce and Social Sciences, 7(2), 243-262.

Hoq, M.Z.; and Ha, N.C. (2009), Innovativeness: Its Antecedents and Impact on SME Business Performance, International Journal of Business and Management, 4(11), 100-110.

Jimenez-Jimenez, D.; and Sanz-Valle, R. (2011), Innovation, Organizational Learning and Performance, Journal of Business Research, 64, 408-417.

Kamasak, R., Yavuz, M., Karagulle, A.O., Agca, T. (2016), Importance of strategic flexibility on the knowledge and innovation relationship: An emerging market study. Journal of Procedia-Social and Behavioral Sciences, 229, 126-132.

Khajeheian, D. (2016), Audience Commodification: A Source of Innovation in Business Models, Technology Innovation Management Review, 6(8), 40-47. 
Kuo, T. (2011), How to Improve Organizational Performance Through Learning And Knowledge?, International Journal of Manpower, 32(5/6), 581-603.

Mahmoud, M. A., Blankson, C., Owusu-Frimpong, N., Nwankwo, S., \& Trang, T. P. (2016). Market Orientation, Learning Orientation and Business Performance: The Mediating Role of Innovation, International Journal of Bank Marketing, 34(5).

Maktabi, S.H.; and Khazaei, A. (2014), The Impact of Organizational Learning on Organizational Performance and Organizational Innovation: Evidence of Bank Industry of Iran, International Journey of Economy, Management and Social Sciences, 3(10), 569573

Muro, M., \& Jeffrey, P. (2008). A critical review of the theory and application of social learning in participatory natural resource management processes. Journal of Environmental Planning and Management, 51(3), 325-344.

Raj, R.; and Srivastava, K. B. L. (2013), The Mediating Role of Organizational Learning on The Relationship Among Organizational Culture, HRM Practices and Innovativeness, Management and Labour Studies, 38(3), 201-223.

Rajala, R., Westerlund, M., Möller, K. (2012), Strategic flexibility in open innovationdesigning business models for open source software. European Journal of Marketing, 46(10), 1368-1388

Sekaran, U. 2003. Research Methods for Business. 2 nd ed. New York: John Wiley and Sons. 